\title{
Cuerpos entre muros: João Gilberto Noll en el hospital
}

\author{
Body between walls: João Gilberto Noll at the hospital.
}

Francisco Gelman Constantin

Universidad de Buenos Aires - Conicet

\begin{abstract}
Resumo
Numa narrativa como a de João Gilberto Noll, na qual se destacam os movimentos de itinerância e transformação, o confinamento no hospital aparece como uma circunstância discordante. Através de Hotel Atlântico (1989) e Canoas e marolas (1999), é possível explorar a ação da palavra literária como uma defesa da autonomia do vivo em relação ao efeito coercitivo dos discursos institucionais que o administram, na aliança soberana ou burocrática da biomedicina e da religião. Construindo diferentes relações entre uma voz narrativa e uma consciência, um eu e um sujeito, os dois romances elaboram o que pode ser dito e escrito pra sustentar o espaço irredutível de uma decisão dos e sobre os corpos contra as pressões do mando autoritário e do circuito comercial.

Palavras-chave: medicina; religião; biopolítica; discurso; fim de vida
\end{abstract}

\section{Resumen}

En una narrativa como la de João Gilberto Noll en la que destacan los movimientos de itinerancia y transformación, el encierro hospitalario aparece como circunstancia discordante. A través de Hotel Atlântico (1989) y Canoas e marolas (1999) es posible explorar la acción de la palabra literaria como una defensa de la autonomía de lo viviente respecto del efecto coercitivo de los discursos institucionales que lo administran, en la alianza soberana o burocrática de la biomedicina y la religión. Construyendo distintas relaciones entre una voz narrativa y una consciencia, un yo y un sujeto, ambas novelas elaboran qué puede decirse y escribirse que sostenga el espacio irreductible de una decisión de y sobre los cuerpos contra las presiones de la rección autoritaria y el circuito mercantil.

Palabras clave: medicina; religión; biopolítica; discurso; final de vida 
La literatura de João Gilberto Noll es en muchos sentidos una literatura del desplazamiento y la transformación, de una dislocación irrefrenable que arrastra a personajes y cosas fuera de cuadro con una celeridad que es tan pronto un incendio como un torrente furioso. Suficientemente lo han notados críticos y críticas que recurren a las figuras del "trânsito", la "errância", las "travessias", "cuerpos que parecen moverse hacia una suerte de desmaterialización", ${ }^{3}$ la "fuga", 4 la "peregrinação", el "nomadismo", 6 o la "deriva constante"7. Vaya ese frenesí en busca de "novas orientações, formas outras de localização" como pretenden algunos ${ }^{8}$ o hacia la pura pérdida de referencias, como sugieren otros, ${ }^{9}$ lo cierto es que la escritura organiza un movimiento que también conmueve en sus fundamentos a aquellos y aquellas que lo experimentan. Por eso no es sorprendente que también buena parte de esas investigadoras e investigadores literarios haya recurrido a Gilles Deleuze para comprender ese dinamismo como el de una potencia de la vida que la empuja más allá de cualquier esencia al impulso del devenir ${ }^{10}$.

Ahora bien, puesto que para la mayor parte de esas aproximaciones la errancia es la operación de la escritura misma y no tanto su punto de origen o de llegada, cabe la pregunta respecto de desde dónde o hacia dónde parten esos cuerpos que se evaden. ¿Hay acaso puntos de fijeza o de permanencia transitoria alrededor de los que arranque ese impulso disparado a la distancia y el extravío? Y tan temprano como con $A$ fúria de corpo, la primera novela de Noll, publicada en 1981, una de las respuestas a esa pregunta es que huyen de la internación. En efecto, el mendigo rubio de $A$ fúria pasa semanas ingresado a una clínica del Instituto Nacional do Seguro Social por desnutrición, en un pabellón sombrío de pacientes indigentes "com nossos pijamas uniformizados sebentos, peçonhentos, manchados, mijados, babados, cagados, fregueses tão a flor da morte que só nos restaba ficar à mercê do INPS dentro das paredes daquela enfermaria e continuar na nossa sujeira, feiúra, insensatez de base" ${ }^{\text {"11. }}$. Y desde el comienzo de la internación el protagonista se prepara para la fuga, primero anticipando ser rescatado por su amante, Afrodita, pero pronto confiando más bien en conspirar con

1 MAGALHÃES, Maria Flávia Armani Bueno. João Gilberto Noll: um escritor em trânsito, 1993. Así como VIDAL, Paloma. "Performance e homoafetividade em dois romances de João Gilberto Noll". E-misférica, 2007, s/p.

2 VIDAL, Paloma. “A escrita performática de João Gilberto Noll”. Teresa, 2010, p. 301, 305. Cfr. también GIORGI, Gabriel. "Lugares comunes: 'vida desnuda’ y ficción”. Grumo, 2008, p. 7.

3 GIORGI, Gabriel. Formas comunes, 2014, p. 265.

4 REZENDE, Marcelo. "Noll parece ansioso por comunicar". Folba de São Paulo, 2002, s/p.

5 NUNES, Tânia Teixeira da Silva. "Homem: vida e contravida em João Gilberto Noll”. Cadernos de Letras da UFF, 2008, p. 249.

6 GARRAMUÑO, Florencia. "Presentación de João Gilberto Noll”. Joaogilbertonoll, 2007, s/p. Así como MACHUCA, Jaqueline Castilho. João Gilberto Noll no cinema: o caso Hotel Atlântico, 2018, p. 23 y ss.

7 AVELAR, Idelber. Alegorías de la derrota, 2000, p. 158.

8 MAGALHÃES, Maria Flávia Armani Bueno. João Gilberto Noll: um escritor em trânsito, 1993, p. 127.

9 GIORGI, Gabriel. Formas comunes, 2014, p. 264.

10 Ibidem, p. 258-259. MAGALHÃES, Maria Flávia Armani Bueno. João Gilberto Noll: um escritor em trânsito, 1993, p.131-132. SÁNCHEZ IDIART, Cecilia. "Error de cálculo. Vida y enfermedad en la literatura latinoamericana", 2017. ALMIRO, Francisca Gilmara da Silva; SILVA, Roniê Rodrigues da. "Subjetivações rizomáticas e a ideia de corpo sem órgãos em A fúria do corpo, de João Gilberto Noll”, 2019.

11 NOLL, João Gilberto. Romances e contos reunidos, 1997, p. 42. 
un adolescente también hospitalizado. Desde su cama o cuando camina por el pabellón en compañía del muchacho, contempla con desagrado la dependencia ajena, odia a aquel viejo que "precisa[va] da enfermeira pra mudar a posição do travesseiro", escucha el "charco de gemidos" y ve pasar las cucarachas ${ }^{12}$. La muerte del viejo yacente, santificado por el fallecimiento, y la violenta acometida del equipo médico contra el adolescente cuando se resiste al tratamiento acaban de colmar la tolerancia del mendigo ante esa cerrazón sombría, pestilente y miserable, y lo mueven finalmente al escape. El mendigo rubio y el "menino" montan a un bus en la puerta del hospital, y la fuga de la internación recomienza la vida itinerante. Es suficientemente visible, en la secuencia que sigue inmediatamente en la novela, la convivencia de ambos "fugitivos" en una comunidad de leprosos traficantes en Cidade de Deus, que la huida no es de la enfermedad, con la que el personaje que narra puede coexistir, sino del enclaustramiento médico en la convalecencia, conflicto que reaparecerá en las novelas de las que trata este artículo pero también en pasajes de $O$ quieto animal da esquina y $A$ céu aberto, y en algunos cuentos ${ }^{13}$.

En esas condiciones, por tanto, puede ser productivo aquí considerar el interés de la narrativa de Noll para unas políticas de la vida, pero más bien en el sentido que dieron a esa indagación investigadores e investigadoras británicas y del Cono Sur que renovaron aquella relación de la biopolítica con la medicina que estaba en algunos textos fundacionales de Michel Foucault ${ }^{14}$. Así, trabajos como los de Nikolas Rose o Sarah Franklin, o como aquellos reunidos en la compilación de Flavia Costa y Pablo Rodríguez La salud inalcanzable, han permitido devolver la pregunta por lo viviente al terreno de saberes y prácticas vinculadas con la biomedicina, y esta

12 Ibidem, p. 45-46.

13 Por caso, como sugirió Florencia Garramuño (conversación personal), ya las primeras páginas publicadas por Noll, el cuento "Alguma coisa urgentemente" que abre O cego e a danarina, nos situaban en el espacio clausurado de la convalecencia (NOLL, 1997, p. 683-689). De hecho, ante el encierro con el cuerpo degradado del padre del narrador, que se acerca entre espasmos a la muerte según parece como consecuencia de la tortura policial, el adolescente responde precisamente con una urgencia de acción que el suspenso del relato impide ver a qué conduciría. Si hay un "foso" entre padre e hijo (CÁMARA, 2017, p. 153), es porque el pasado revolucionario del padre no puede ser heredado como un conjunto de enunciados programáticos, sino como una relación inventiva con el modo en que las experiencias políticas inhieren en los cuerpos -exentos, como ha señalado Flora Süssekind, de heroicidad (2003, p. 80). Por eso, al mismo tiempo que proyecta la acción urgente en la que acabar de algún modo con esa parálisis moribunda, el hijo intenta siquiera heredar la convalecencia misma, inventando ante su amigo Alfredinho una enfermedad propia. Como argumenté en otra parte (GELMAN CONSTANTIN, 2020 y 2019), en los años ochenta la enfermedad no es una forma de despolitización, sino que entre la crisis del sida, la participación de profesionales de la salud en las violencias de estado y los movimientos de desmanicomialización, la medicina es un territorio de disputa política y experimentación colectiva sobre las formas de cuidado de sí y de los otros y otras. En este caso, el narrador de "Alguma coisa" imagina el retiro hacia la enfermedad como la huida de las obligaciones escolares y la oportunidad de investigar sus propios placeres corporales, por muy ficticia que sea la historia que cuenta a Alfredinho. Incluso si no habláramos simplemente de una "derrota del proyecto revolucionario", ciertamente los ochenta trajeron la invención de "nuevas éticas y políticas del cuerpo y la sexualidad" (GIORGI, 2014, p. 258) que suponen una relación problemática con el encierro de los cuerpos que padecen.

14 Especialmente, "La crisis de la medicina o la crisis de la antimedicina", "Historia de la medicalización" e "Incorporación del hospital a la tecnología moderna", 1996, p. 67-120. 
parece ser una condición estimulante para pensar algunas formas de inscripción de la narrativa de Noll ${ }^{15}$.

Lo biomédico, así, es uno de los campos de acción de la literatura de Noll a lo largo de buena parte de su obra, en esa versión industrial y mercantilizada entre cuyos profesionales y pacientes-clientes-adictos el mendigo rubio de $A$ fúria sitúa filosamente la "profissão do me-dáme-dá" ${ }^{16}$. Dentro de esa línea discontinua a través de diversos cuentos y novelas, en este artículo el foco estará puesto en dos novelas posteriores, distantes diez años entre sí: Hotel Atlântico, publicada en 1989, y Canoas e marolas, publicada en 1999. Con ellas, se tratará de explorar el espacio institucional de un hospital o una clínica como ocasión de una teoría sobre las relaciones entre el discurso y los cuerpos, condensada alrededor del problema de las decisiones de final de vida.

Es que con Noll, y enlazándolo a diversas reflexiones antropológicas, lingüísticas éticas en el territorio de la medicina, ${ }^{17}$ el modo específico en el que el discurso médico dé forma a cuerpos particulares puede situarse en la relación entre ese discurso y el orden de la decisión, terapéutica o de otro tipo. Cabría situar esa relación como el lugar de un salto irreductible, que no puede eliminarse desde ninguno de los dos lados, en el que la decisión no viene resuelta por el discurso que la enmarca, pero no podría ocurrir sin esa condición. A la expectativa de la eliminación del salto entre discurso y decisión corresponden las formas simétricas del autoritarismo y la burocracia: de un lado la cara iridiscente de los pequeños soberanos que se dan por exentos de respaldar su decisión en cualquier marco discursivo; del otro, su cara gris, allí donde pretenden que no hay ninguna decisión que tomar, que el solo rodar del circuito discursivo resuelve todas las contingencias ${ }^{18}$.

A la teoría de ese salto irreductible entre discurso y decisión corresponde en el psicoanálisis la doctrina del acto. En efecto, en la conferencia de fundación de la Escuela Francesa de Psicoanálisis, "Acte de fondation", ${ }^{19}$ Jacques Lacan enlazaba la teoría del acto con la teoría del discurso bajo la forma de un desajuste. Se planteaba inicialmente el psicoanalista que "[sobre] esta fundación, podemos elevar en principio la cuestión de su relación a la enseñanza, que

15 ROSE, Nikolas. The Politics of Life Itself. Biomedicine, Power, and Subjectivity in the Twenty-First Century, 2007. FRANKLIN, Sarah. Embodied Progress. A Cultural Account of Assisted Conception, 1997. COSTA, Flavia; RODRÍGUEZ, Pablo (comps.). La salud inalcanzable. Biopolítica molecular y medicalización de la vida cotidiana, 2017.

16 NOLL, João Gilberto. Romances e contos reunidos, 1997, p. 34.

17 LUPTON, Deborah. Medicine as Culture. Illness, Disease and the Body, 2012, p. 106-107. JONES, Rodney H. "Discourse and Health Communication", 2015, p. 841. BETANCOURT BETANCOURT Gilberto de Jesús; RIVERO CASTILLO, José Armando. "Limitación del esfuerzo terapéutico: aspectos religiosos y culturales", 2015, p. 145-162.

18 El interés por analizar no solo autoridades mayores de estado, sino también esos "pequeños soberanos" dispersos en las instituciones minutas de gobierno estaba en BUTLER, Judith. "Detención indefinida”, 2006, p. 92. Lo que ella consideraba sobre la administración de la justicia militar, vale aquí para administraciones hospitalarias y profesionales particulares.

19 Autres écrits, 2001, p. 229-241. La palabra francesa "acte" significa tanto "acto" como "acta"; la conferencia de Lacan se deslizaba continuamente entre uno y otro sentido, y corresponde recuperar su conexión en cada aparición de cualquiera de las dos traducciones, que es precisamente el vínculo problemático entre la acción (acto) y su condición discursiva (acta). 
no deja sin garantía la decisión de su acto", para poco después responder a ese interrogante, en recapitulación de su propia doctrina, con "un desajuste [décalage] del discurso, sobre el que Lacan eleva el acto". Un acto, entonces, la decisión de un acto o el acto como decisión, se encuentra retrospectivamente garantizado en una enseñanza discursiva, pero el instante de su alzamiento no corresponde a la ratificación de ese discurso, sino a su desajuste, a una soltura o distancia que no puede cubrir la singularidad del acto. La extrañeza constitutiva de la decisión, lo irreductible de su distancia respecto del discurso en el que hallará garantía, es acaso una de las explicaciones de la condescendencia con la que la institución médica hace lugar al ingreso de la religión. Discurso doblemente afecto al colapso de la distancia entre acto y decisión al que nos referíamos más arriba -entre burocrático y autoritario-, la religión promete resolver la angustia de ese hiato con una justificación y un mandato trascendentes ${ }^{20}$. Ya advertiremos hasta qué punto esa intrusión se hace patente en nuestras novelas. En cualquier caso, en el marco de la muerte medicalizada, el rango que va de la decisión absurda (privada de fundamentos, irracional, imposible de justificar con una referencia discursiva) a la determinación burocrática es especialmente crítico, y es a ella que están dedicadas Hotel Atlântico y Canoas e marolas.

Hotel Atlântico relata en primera persona los últimos meses de vida de un actor de telenovelas con una afección que no recibe un nombre fehaciente, pero cuyos signos son constatados en tono sombrío desde las primeras páginas:

\footnotetext{
Delante del espejo, miré mis ojeras profundas, la piel escarapelada, los labios resecos, introduje mi lengua por la carie inflamada de un diente, pensé que no valía la pena seguir allí, contabilizando señales de que mi cuerpo se estaba deteriorando. Había llegado la hora de partir ${ }^{21}$.
}

Vejez, alcoholismo, sepsis, sugerencias diagnósticas múltiples que nunca son ratificadas, sino que se acumulan como otras coordenadas variables para la ronda de un narrador que "está sempre em movimento" 22 . En este caso, el viaje conduce al protagonista a través de varias localidades del sur de Brasil hasta el día en que despierta en la cama de una clínica en Arraiol, con una pierna amputada. La elipsis narrativa de esa cirugía coincide con la ausencia de consciencia del narrador, que se recobra para encontrar en falta no solo un lapso de tiempo sino una extremidad; en ese vacío se inscribe una decisión médica, en ausencia del yo, que el cirujano a cargo de la clínica -que se convertirá también en alcalde del pueblo- ha tomado sin mediar la palabra del paciente. La amputación, como acto médico, es el producto de un discurso, pero

\footnotetext{
20 Mladen Dolar se ha explayado sobre la idea de que en el cristianismo el texto doctrinario -diríamos aquí, el discurso religioso en sentido estricto- es suplementado por una autoridad trascendente que lo transforma en un mandato de acción, el gesto puro (vacío de contenido proposicional) de la voz de Dios, único sostén del carácter imperativo de la letra teológica. A Voice and Nothing More, 2006, p. 53.

21 NOLL, João Gilberto. Hotel Antlántico, 2014, p. 14-15.

22 BORGES FILHO, Oziris. "Sob o signo de Caronte: Hotel Atlântico de João Gilberto Noll”. Anuário de Literatura, 2010, p. 8.
} 
uno en el que el paciente no tiene ningún lugar como sujeto de una palabra; y de ese modo ese espacio desaparece también de la narración, en una ausencia que difícilmente podría pasar inadvertida. Si, en la pérdida de sí, la decisión de oficio del médico podría aparecer como una necesidad práctica, la novela insiste en el espacio de gobierno que ocupa el personaje del doctor Carlos; en palabras del enfermero Sebastião, principal interlocutor y aliado del narrador en la novela, "El dueño del cotarro aquí es el doctor Carlos, es él quien da las órdenes"23. Fuera del acompañamiento solidario de Sebastião, apenas el gesto discreto de un residente que no toma notas de las peroratas del doctor Carlos frente al paciente sugiere límites en su capacidad de mando, como si ese gesto de inmovilizar su bolígrafo señalara una barricada posible frente al avance del discurso del cirujano.

Donde un enfermero y un residente ponen reparos a la autoridad constituida, el mando de la clínica puede apuntalarse con otros discursos. Como ha señalado una crítica, en la novela abundan las referencias religiosas ${ }^{24}$. Ya antes de su llegada al hospital, el protagonista se ve forzado por las circunstancias a fingirse sacerdote para otorgar la extremaunción a un moribundo. En la clínica de Arraiol, la capilla es el lugar de encuentros sexuales frustrados con la hija del médico, y donde se emplea especialmente un organista. Lo más sugestivo es acaso, sin embargo, que el doctor Carlos envía al protagonista de Hotel Atlântico una vida de San Francisco de Asís para que lea en la cama, como si fuera un recurso integral en la cura. Hastiado, el paciente exige a Sebastião apartar ese libro de su vista y esa primera resistencia a un texto que sabe cómplice de su postración encabeza un nuevo movimiento de partida, que lo lleva a reclutar la ayuda del enfermero para escapar de la clínica y de la "tiranía del doctor Carlos" 25. El recomienzo del viaje equivale a la renuncia a la posibilidad de una cura, pero conduce a una romantizada muerte apacible en brazos del enfermero, sobre la arena y luego de mirar el mar por primera vez en su vida:

\footnotetext{
Después me quedé ciego. Ya no pude ver ni el mar ni a Sebastião. Solo me quedaba respirar, respirar lo más profundo posible. Y me sentí listo para introducir en mis pulmones todo el aire, poco a poco. En esos segundos en que llenaba mis pulmones de aire, sentí que Sebastião me tomaba de la mano.

Sebastião tiene fuerza, pensé, y fui soltando el aire, despacio, muy despacito, hasta el final ${ }^{26}$.
}

El final que enuncian las palabras coincide con el final de la novela, en esa misma adherencia entre escritura y posibilidades narrativas del yo que advertíamos antes en el despertar del paciente amputado en la clínica. El relato se clausura dentro de un dispositivo narrativo en el que la consciencia coincide con la narración, bajo una lógica de la presencia a sí que condice

23 NOLL, João Gilberto. Hotel Antlántico, 2014, p. 87.

24 MAGALHÃES, Maria Flávia Armani Bueno. João Gilberto Noll: um escritor em trânsito, 1993, p. 120.

25 NOLL, João Gilberto. Hotel Antlántico, 2014, p. 109.

26 Ibidem, p. 120. 
perfectamente con esa ausencia de analepsis o prolepsis que señaló con justeza Maria Flavia Armani Bueno Magalhães, ${ }^{27}$ y que distingue Hotel Atlântico nítidamente de los saltos temporales de Bandoleiros o de los paréntesis alucinatorios de A fúria do corpo. La consistencia del yo que narra dentro de ese verosímil la aparta de casi todas las demás novelas, incluso si -tal como ha señalado Florencia Garramuño- no conviene apresurarse a identificar la crisis de la identidad con la desaparición del sujeto ${ }^{28}$. En Hotel Atlântico toda la narración cabe dentro del yo, pero ese yo no cabe dentro de los discursos que condicionan los actos sobre su cuerpo; esos caudales verbales lo cercan, entre la religión y una medicina soberana, hasta no dejar otra alternativa que la salida.

Con la expresión que sugiere la muerte del narrador se acaba la narración y en ese pliegue se consolida el encierro de la novela en la perspectiva de quien muere y ha podido decidir dónde y cómo hacerlo. Pero si esa posición parece unívoca y reconciliatoria en el final, ¿qué ocurre, retrospectivamente, con la elipsis anterior, durante la amputación? ¿Cómo relacionarse con las decisiones de vida y muerte sobre un cuerpo biológico cuando falta una consciencia, narrativa y normativa, que tome esas decisiones, pero se ha desacreditado la convergencia entre discurso médico y discurso religioso que pretendía reemplazarla? Hacia allí va Canoas e marolas.

Si la premisa editorial de esta otra novela breve publicada por Noll en 1999 es la de un texto sobre el pecado de la pereza, ${ }^{29}$ el punto de partida del relato es sin embargo el viaje del narrador y protagonista, João, a una isla frente a la costa brasileña, en busca de una antigua novia suya y la hija que han tenido juntos, ambas llamadas Marta ${ }^{30}$. João había conocido a Marta como enfermera cuando estaba internado por un accidente de tránsito y sabe que la hija de ambos ha estudiado medicina. Puede imaginarla en el futuro tomándole la presión o recomendándole una dieta, pero al llegar a la isla se entera de su trabajo en un protocolo para enfermos terminales llamado "Ablação da Mente":

Um método relativamente simples que consistia em levar o doente até o outro lado como se o terapeuta estivesse transportando o agonizante a um novo paraíso, paraíso criado não por profetas mas por humanos como a gente, sem ostentar, portanto, pompas transcendentais.

O terapeuta tinha que fazer com que o enfermo voltasse a acreditar no poder da luz, isso, no poder divinatório da luz que está sim no outro lado da vida, pois a luz permanece além ou aquém das trincheiras genitais que nos procriaram e depois nos iludiram em seus cárceres desejantes, sim, a

27 MAGALHÃES, Maria Flávia Armani Bueno. João Gilberto Noll: um escritor em trânsito, 1993, p. 198.

28 GARRAMUÑO, Florencia, Mundos comunes, 2015, p. 86n.

29 MACHUCA, Jaqueline Castilho. João Gilberto Noll no cinema: o caso Hotel Atlântico, 2018, p. 40.

30 La duplicación del nombre señala desde muy temprano la progenie como un sentido posible de trascendencia (biológica) ante la muerte. El narrador se volverá más tarde sobre esa posibilidad como una vía muerta cuando asista al nacimiento de "su" nieto: "Aproximei-me para olhá-lo, mas de fato não vi nada naquele minúsculo corpo, todo sujo de fluidos de vida, que pudesse ser chamado de meu. Nenhum detalhe nas asas do nariz, orelhas, pés. Eu não estava prolongado em nenhum pormenor daquele boneco de carne; (...) vivíamos para acreditar em lendas de semelhanças físicas, em prolongamentos de nossa personalidade nos nossos descendentes, em bolações genéticas futuristas, nessas coisas, enquanto o pobre cara que habita nosso corpo não quer mais se iludir com lábias de linhagens" (NOLL, 1999, p. 78-79). 
luz permanece lá, aquém o além, não importa, pois são conceitos que vão dar no mesmíssimo lugar, fora dos pontos limites de uma extensão de vida, espaço inconcebível talvez para quem ainda se encarcera em anos; lá então, nesse espaço, começa a reinar a festa de luz, tão soberba que a duração aí se rende como se gozasse, deixando que a exaltação da luz coagule e poreje sua independência em nós ${ }^{31}$.

Sin pompas trascendentales, quizá, por la sobriedad retórica de la luz, pero lleno de promesas de trascendencia. El método de ablación mental inculca en el moribundo la creencia en un más allá o más acá de la vida, más allá o más acá de la finitud de los cuerpos deseantes. Más que ser "retratada en la novela como un sustituto moderno de la religión", 32 la ciencia biomédica recluta herramientas discursivas de la religión para ofrecer una garantía consolatoria, respaldada por "um fenômeno físico comprovado" 33 . La "melhor das mortes" convoca tanto a sacerdotes cuanto a médicos, contaminados entre sí, mezclados sus discursos en una sola "semântica ensandecida" 34 . El sentido de esa semántica enloquecida es la dirección de trascendencia misma, la imposición de un significado ascencional al morir.

Rita Charon, la médica neoyorkina inventora de la medicina narrativa, declaraba que

una medicina científicamente competente no puede por sí sola ayudar a un o una paciente a lidiar con la pérdida de la salud y hallar sentido en la enfermedad y la muerte. Junto con la creciente experticia científica, las y los doctores necesitan la experticia de escuchar a sus pacientes, de entender lo mejor que puedan las penurias de la enfermedad, de honrar los sentidos de las narrativas de enfermedad de sus pacientes y de emocionarse con lo que contemplan para poder actuar de parte de sus pacientes ${ }^{35}$.

La defensa de Charon de unas competencias específicas de escucha señalaba la incompletud del discurso médico como contenido de una enseñanza, allí donde no puede ofrecer a los y las médicas la capacidad de operar sobre los sentidos de la muerte. Pero en la presunción de que la mejor de las muertes requiere esa presencia de sentido, la medicina narrativa corría el riesgo de convertirse, como se temió del psicoanálisis, ${ }^{36}$ en una versión secularizada de la religión, que conserve sus medios o se le haga solidaria. Esa es sin duda la vía que toman los relatos del paraíso de luz presuntamente laico en Canoas e marolas, su "doutrina médico-espiritual" dirigida a "superar a tristeza, a covardia diante do fim", con "a certeza de que o desaparecimento era

31 Ibidem, p. 20-21.

32 BRAYNER, Aquiles Alencar. The literature of senses: body, corporeal perception and aesthetic experience in the work of João Gilberto Noll, 2009, p. 145.

33 NOLL, João Gilberto. Canoas e marolas, 1999, p. 24.

34 Ibidem, p. 21.

35 CHARON, Rita. Narrative Medicine: Honoring the Stories of Illness, 2002, p. 3.

36 SOLER, Colette. Les affects lacaniens, 2011, p. 171-172. 
o melhor dos caminhos" ${ }^{37}$. Muy lejos del autoritarismo del doctor Carlos de Hotel Atlântico, el programa de ablación mental sumerge la dimensión del acto en el torrente verbal, como si no hubiera ninguna decisión que tomar, apenas la insensible, adormecida, entrada en el programa.

A las certezas luminosas del continuo discursivo del programa, su "roda interminável", 38 la novela opone la propia enunciación narrativa de João, del despliegue retórico sensual al encuentro igualmente jubiloso con una lengua muda. Cuando ya han internado al narrador como un paciente más del protocolo para enfermos terminales, João encuentra entre quienes lo cuidan a una enfermera coreana que apenas habla portugués, pero con quien logra mantener alguna clase de diálogo hecho de gestos y medias palabras:

entre mim e a enfermeira coreana jamais surgiu uma semântica suficientemente madura para ser relatada. O que se desenhava entre nós não era propriamente uma história infantilizada, pré-alfabeto, mas pequenos veios já bastante sucateados, e que ainda conseguiam nos retroceder de alguma forma a uma lenda baldia onde figurávamos palidamente, sempre em tom menor ${ }^{39}$.

Aunque el enfrentamiento sea más discreto que aquel otro gesto relatado en la novela de morder al hombre calvo que en cierto momento le ofrece la extremaunción, la semántica inmadura se opone abiertamente a la semántica enloquecida del programa de ablación mental, tanto como la leyenda baldía a las historias de trascendencia. Vaciada y melancólica -pálida y en tono menor-, la leyenda ya no puede ser una narración, algo relatable, sino apenas un ademán de decir a alguien, "a escandida carência dando margem a apenas uma palavra, curta, breve, seca: Não..." ${ }^{40}$.

Esa retracción de la lengua a un parco "não" conviene al abandono del discurso que le ofrecen. João recibe la invitación a integrarse al lazo de cuidado médico-religioso, pero a condición de ubicarse en un lugar preciso de ese discurso, con los afectos requeridos por esa estructura:

Era isso que deveria estar martirizando os membros do Programa: terem de contemplar em mim um estado vegetativo, quase, morte sem óbito, e não uma indolência caricata, angustiosa, agônica, delirante, alucinada por vezes, prestes a ser recebida no fausto da redenção para o convívio. E ficava ali, ele, esse fulano que era eu, sem queixas aparentes, sem vivos procedimentos, ciscando ociosamente num terreno de olímpica indeterminação ${ }^{41}$.

37 NOLL, João Gilberto. Canoas e marolas, 1999, p. 95, 29-30.

38 Ibidem, p. 64.

39 Ibidem, p. 76.

40 Ibidem, p. 56.

41 Ibidem, p. 75. 
El discurso médico-religioso del hospital isleño hace sitio al narrador, pero solo si está en condiciones de enunciar en su interior quejas angustiadas, que justifiquen la respuesta terapéutica del programa para "desdenhar dores, mazelas, infortúnios", garantizando sus decisiones; y la eficacia del programa abre la puerta al otro rango de afectos, esperanzados: "queriam me ver recuperando-me da vida, partindo desse mundo com a ilusão crescente de que agora sim começaria a fazer sentido" ${ }^{42}$. Pero en ningún caso hay un lugar para la sobriedad del protagonista de la novela; el discurso de la clínica no puede hacer nada con ese sujeto, ni soportarle ningún enunciado o decisión. João insiste sin embargo en no "melodramatizar", en "romper com esse cárcere romântico e tentar nos educar para a disciplinada ilusão que não atinge os sentidos, toda branca e asséptica (...), isso sim nos parecia verdadeiramente terapêutico, rejuvenescedor de nosso fim" ${ }^{43}$. La ilusión disciplinada puede ser muda, como la leyenda baldía, pero ¿cómo señalar entonces el apartamiento de los discursos a mano, que hace otro lugar para los cuerpos y sus decisiones? ¿Pueden decirse algo más allá del "não" o cuando ya no hay quién lo pronuncie?

El camino alternativo, como en las otras obras, exige la huida -menos o más literaldel hospital pero ¿qué puede decirse de él?, ¿cómo se lo narra? En el silencio, una máquina neurológica puede identificar ciertas ondas electromagnéticas con la presencia de dolor, pero esa detección no equivale al enunciado de una queja y el narrador de Canoas e marolas denuncia la imposición de un sentido del dolor como parte del discurso médico:

O que não dói para você eu acho é este estado meio anestesiado furtivo invisível em que me encontro nesse ponto da estrada, isso é que não dói para você. Pois não dói mesmo. Aqui a dor dói de não doer entende? Por não doer é que dói, se bem me explico ${ }^{44}$.

La ausencia de dolor puede doler, allí donde la insensibilización anestésica puede ser menos un servicio a quien sufre que a quienes lo rodean. ${ }^{45}$ No obstante, cuando no hay voz que desambigüe, quien calla concede.

Privado del soporte del discurso hospitalario, el narrador de la novela recurre en las páginas finales a un territorio alternativo del lenguaje. Se ve a sí mismo ya sin fuerzas viajando con indígenas en un colectivo hasta un valle desconocido, se ve esfinge entre los "indios", divinizado y paralítico, teniendo conversaciones aforísticas y sintiendo el viento sobre su cara. Un gran relato mítico que llena la leyenda baldía de imágenes fulgurantes, escenas tan pictóricas

42 Ibidem, p. 38, 62.

43 Ibidem, p. 72.

44 Ibidem, p. 81-82.

45 Sobre la anestesia como un servicio a los médicos, BUCK-MORSS, Susan. "Aesthetics and Anaesthetics: Walter Benjamin's Artwork Essay Reconsidered", 1992, p. 27-28. Para una reivindicación del dolor como potestad de un sujeto, vale la pena remitirse a la película de Kirby Dick Sick: The Life and Death of Bob Flanagan, Supermasochist (1997). 
o casi fílmicas que llevan a leerlas dentro de la novela como la alucinación de un ido, como los productos de la imaginación del estado comatoso que se anuncia muchas páginas atrás ${ }^{46}$.

Lo sugestivo, de la enunciación del coma a todo lo que la sigue, es que ya no hay lugar para el cuidadoso verosímil de Hotel Atlántico en el que el enunciado coincide con las posibilidades del narrador personaje para la transmisión de un relato. El discurso mítico ocurre precisamente en el lugar de una voz encerrada en el cerebro insomne, para llenar el espacio de ese repetido "no" que João querría enunciar. Hurtadas las posibilidades que ofrezca el discurso médico para que un paciente declare sobre su dolor y decida sobre su vida, y abierto el marco en que alguien lo haga en su lugar, la narración literaria produce un enunciado que no puede asignarse a nadie, que ningún narrador "de carne y hueso" podría asumir en un hospital si en efecto ha quedado orgánicamente más allá del lenguaje. Pero precisamente por eso se impone su necesidad: en esa imposibilidad de ser el enunciado efectivo de un o una paciente, la interferencia literaria le da un lugar en el que hacer obstáculo a la imposición de sentido de la biomedicina o de su colusión con la religión. Donde el yo ya no puede hablar pero no se quiere confiar la decisión ni a la soberanía -médica o familiar- ni a al rodar insensible de un discurso burocrático, un enunciado sin fundamento, sin origen posible, que puede decirse literario, encuentra su pertinencia.

En ese discurso más allá del yo, pero exento también del automatismo de la burocracia, se sostiene el espacio de la singularidad de un cuerpo, y la defensa de una instancia irreductible de decisión sobre su suerte, en la que la narración literaria objeta los modos institucionales de gestión de la vida. En ese decir imposible de adjudicar, la palabra literaria defiende un espacio político en que el circuito idiota del discurso no puede colapsar la decisión sobre qué hacer con cada cuerpo en la generalidad de un procedimiento normado, ni habilitar la orden incondicionada de una autoridad soberana. Lo narrado en las novelas puede sugerir apenas las alternativas de la sumisión o la huida, pero la escritura misma como acto abre el espacio de otras decisiones futuras: crea un discurso en el que los cuerpos puedan sostener su arbitrio, incluso si ya han perdido el yo, e invita acaso también a hacerle a ese discurso un lugar dentro, sin duda bien lejos de la certidumbre religiosa, pero quizá proponiendo también otra medicina posible. De Hotel Atlántico a Canoas e marolas, las novelas de Noll elaboran los límites de lo que puede ser narrado y escrito, lo decible y lo imaginable, entre los bordes del yo y de una subjetividad cualquiera, donde la administración industrial de lo viviente se enfrenta a los impulsos autónomos de una decisión sobre sí. Sobre ese conflicto se perfila, podríamos suponer, cualquier ulterior vía de escape, fuera o dentro de los muros.

46 "Eu entrava num coma branco, sem razão ou sentido, bem provável, e, se assim permanecesse, acabaria reconstituindo por inércia um certo gozo, renitente, fino, restrito, infra-humano (...) - com esse precário gozo eu permaneceria ali deitado naquela mesa cirúrgica pelo resto dos dias; aí não importava nada do que acontecesse no padrão externo, eu apenas recebendo soro na veia (...). Mas não, não, falei para meus miolos insones. Nessa condição em que me acho me exaspera estar completamente dependente desses fulanos do Programa de Ablação da Mente. Desses caras que fuxicam para me injetar alguma reação distinta da inércia... mas não conseguirão, verão." (NOLL, 1999, p. 70). 


\section{Referências}

ALMIRO, Francisca Gilmara da Silva; SILVA, Roniê Rodrigues da. "Subjetivações rizomáticas e a ideia de corpo sem órgãos em A fúria do corpo, de João Gilberto Noll”. Graphos, n. 1 (21), 2019. p. 261-275.

AVELAR, Idelber. Alegorías de la derrota. Santiago: Cuarto propio, 2000.

BETANCOURT BETANCOURT, Gilberto de Jesús; RIVERO CASTILLO, José Armando. "Limitación del esfuerzo terapéutico: aspectos religiosos y culturales". En: Humanidades Médicas, n. 15 (1), 2015. p. 145-162.

BORGES FILHO, Oziris. "Sob o signo de Caronte: Hotel Atlântico de João Gilberto Noll". En: Anuário de Literatura, n. 1 (15), 2010. p. 7-34.

BRAYNER, Aquiles Alencar. The literature of senses: body, corporeal perception and aesthetic experience in the work of João Gilberto Noll. Köln: Lambert Academic Publishing, 2009.

BUCK-MORSS, Susan. "Aesthetics and Anaesthetics: Walter Benjamin's Artwork Essay Reconsidered”. October, n. 62, 1992, p. 3-41.

BUTLER, Judith. "Detención indefinida". En: BUTLER, Judith. Vidas precarias. Buenos Aires: Paidós, 2006. Trad. de RODRÍGUEZ, Fermín.

CÁMARA, Mario. "Vivir con fantasmas". En: CÁMARA, Mario. Restos épicos. Buenos Aires: Libraria, 2017, p. 133-173.

CHARON, Rita. Narrative Medicine: Honoring the Stories of Illness. New York: Oxford University Press, 2002.

COSTA, Flavia; RODRÍGUEZ, Pablo (comps.). La salud inalcanzable. Biopolítica moleculary medicalización de la vida cotidiana. Buenos Aires: Eudeba, 2017.

DOLAR, Mladen. A Voice and Nothing More. Cambridge: MIT Press, 2006.

FOUCAULT, Michel. "La crisis de la medicina o la crisis de la antimedicina", "Historia de la medicalización" e "Incorporación del hospital a la tecnología moderna". En: FOUCAULT, Michel. La vida de los hombres infames. Trad. de Julia Varela e Fernando Álvarez-Uria. La Plata: Altamira, 1996. p. 67-120.

FRANKLIN, Sarah. Embodied Progress. A Cultural Account of Assisted Conception. New York/ London: Routledge, 1997.

GARRAMUÑO, Florencia. Mundos comunes. Buenos Aires: FCE, 2015.

GARRAMUÑO, Florencia “Presentación de João Gilberto Noll”. Joaogilbertonoll, 2007. Disponible en: http://www.joaogilbertonoll.com.br/baires.htm. Acceso en: nov. 2015.

GELMAN CONSTANTIN, Francisco. Formas de lo viviente en América Latina (1980-2019). Incursiones literarias sobre la biomedicina. Buenos Aires: Universidad de Buenos Aires, 2020. 
GELMAN CONSTANTIN, Francisco. "Poesía y Humanidades Médicas desde el Cono Sur: algunas proposiciones a partir de la obra de Virna Teixeira". Physis, n. 29.4, 2019. p. 1-25. Disponible en: https://www.scielo.br/pdf/physis/v29n4/0103-7331-physis-29-04-e290409. pdf. Acceso en: ene. 2020.

GIORGI, Gabriel. Formas comunes. Buenos Aires: Eterna Cadencia, 2014.

GIORGI, Gabriel. “Lugares comunes: 'vida desnuda' y ficción”. Grumo, n. 6, dic. 2008. p. 3-17. Disponible en: https://3e61dffc-69af-4723-8f64-2670f9f81bc6.filesusr.com/ugd/ de3363_ff07c94074ce428982fedc381d930c48.pdf. Acceso en: may. 2018.

JONES, Rodney H. "Discourse and Health Communication". En: TANNEN, Deborah; HAMILTON, Heidi E.; SCHIFFRIN, Deborah (eds.). The Handbook of Discourse Analysis. Oxford: Blakwell, 2015. p. 841-857.

LACAN, Jacques. Autres écrits. Paris: Seuil, 2001.

LUPTON, Deborah. Medicine as Culture. Illness, Disease and the Body. London/ Los Angeles: Sage, 3. ed., 2012.

MACHUCA, Jaqueline Castilho. João Gilberto Noll no cinema: o caso Hotel Atlântico. 183f. Tese (Doutorado) - Universidade Estadual de Campinas, Instituto de Estudos da Linguagem, Campinas, 2018. Disponible en: http://repositorio.unicamp.br/jspui/bitstream/ REPOSIP/333262/1/Machuca JaquelineCastilho D.pdf. Acceso en: 24 set. 2020.

MAGALHÃES, Maria Flávia Armani Bueno. João Gilberto Noll: um escritor em trânsito. 345f. Dissertação (mestrado) - Universidade Estadual de Campinas, Instituto de Estudos da Linguagem, Campinas, SP, 1993. Disponible en: http://www.repositorio.unicamp.br/handle/ REPOSIP/269156. Acceso en: 24 set. 2020.

NOLL, João Gilberto. Hotel Atlántico [pt. 1989]. Buenos Aires: Adriana Hidalgo, 2014. Trad. de CÁRDENAS, Juan Sebastián.

NOLL, João Gilberto. Canoas e Marolas. Rio de Janeiro: Objetiva, 1999.

NOLL, João Gilberto. Romances e Contos Reunidos. São Paulo: Companhia das Letras, 1997.

NUNES, Tânia Teixeira da Silva. "Homem: vida e contravida em João Gilberto Noll", Cadernos de Letras da UFF, n 34, 2008. p. 249-264.

REZENDE, Marcelo. "Noll parece ansioso por comunicar". Folba de São Paulo, n. del 9 de nov. 2002, s/p. Disponible en: https://www1.folha.uol.com.br/fsp/ilustrad/fq0911200217. htm. Acceso en: nov. 2015.

ROSE, Nikolas. The Politics of Life Itself. Biomedicine, Power, and Subjectivity in the Twenty-First Century. Princeton/ Oxford: Princeton University Press, 2007.

SÁNCHEZ IDIART, Cecilia. "Error de cálculo. Vida y enfermedad en la literatura latinoamericana". Kamchatka, n. 10, dic. 2017. p. 163-178.

SOLER, Colette. Les affects lacaniens. Paris: Presses Universitaires de France, 2011. 
SÜSSEKIND, Flora. Vidrieras astilladas. Trad. De María Teresa Villares. Buenos Aires: Corregidor, 2003.

VIDAL, Paloma. “A escrita performática de João Gilberto Noll”. Teresa, n. 10-11, 2010. p. 300-311. Disponible en: http://www.revistas.usp.br/teresa/article/view/116866/114405. Acceso en: jun. 2018.

VIDAL, Paloma. "Performance e homoafetividade em dois romances de João Gilberto Noll". E-misférica, n. 4 (1), s/p, 2007. Disponible en: https://hemisphericinstitute.org/en/emisferica41/4-1-essays/performance-e-homoafetividade-em-dois-romances-de-joao-gilberto-noll.html. Acceso en: oct. 2015.

Submissão: $16 / 04 / 2020$

Aceite: $12 / 06 / 2020$

https://doi.org/10.5007/2176-8552.2019.e73030

Esta obra foi licenciada com uma Licença Creative Commons Atribuição-NãoComercial 4.0 Internacional. 